\title{
PENGARUH E-COMMERCE DAN PROMOTION SALE TERHADAP PENJUALAN PT. TOYOTA-ASTRA MOTOR
}

\author{
Moh.Nurhidayat ${ }^{1}$, Helmi Chaidir ${ }^{2 *}$ \\ Institut Teknologi dan Bisnis Ahmad Dahlan Jakarta
}

\begin{abstract}
ABSTRAK
Tujuan penelitian ini adalah untuk menjelaskan pengaruh e-commerce dan promotion sale terhadap penjualan pada PT. Toyota-Astra Motor. Metode penelitian yang digunakan adalah deskriptif asosiatif kuantitatif. Populasi dalam penelitian ini yaitu pelanggan PT. ToyotaAstra Motor Jl. Laks. Yos Sudarso, Jakarta Utara. Pengambilan data menggunakan purposive sampling yang didistribusikan kepada 65 responden. Teknik pengumpulan data dalam penelitian ini menggunakan kuesioner. Metode yang digunakan adalah regresi linear berganda, dengan bantuan software SPSS 19. Hasil penelitian ini menunjukkan bahwa $e$ commerce dan promotion sale secara simultan berpengaruh terhadap penjualan. Artinya kontribusi e-commerce dan promotion sale adalah 66,1\%. sedangkan sisanya 33,9\% dijelaskan oleh variabel lain diluar penelitian ini. Secara parsial, e-commerce tidak berpengaruh signifikan terhadap penjualan dan promotion sale berpengaruh signifikan terhadap penjualan. Berdasarkan dari hasil kuesioner, penulis memberikan saran sebagai berikut. Pertama, Perusahaan harus meningkatkan respon/umpan balik dengan mempersingkat waktu tunggu balasan. Agar kemudahan dan kecepatan pada e-commerce dapat terwujudkan dan pelanggan berminat membeli melalui e-commerce. Kedua, Perusahaan harus meningkatkan iklan platform resmi Toyota Indonesia agar lebih dikenal lagi oleh pelanggan. Ketiga, Perusahaan harus selalu menampilkan syarat untuk mendapatkan harga promo. Agar harga promo yang diadakan mudah didapatkan oleh pelanggan.
\end{abstract}

Kata Kunci: E-commerce, Promotion sale, Sales.

\section{PENDAHULUAN}

Penggunaan e-commerce sudah banyak dilakukan oleh pedagang-pedagang sekarang ini, baik untuk industri pabrikan maupun home industri. Penjualan melalui e-commerce dinilai lebih mudah dan praktis dibandingkan dengan cara konvensional. Selain itu, cakupan penjualan pun semakin besar, tidak hanya di daerah penjual tersebut berada tetapi dapat mencakup nasional dan bahkan internasional. Penjualan melalui $e$ commerce mampu membuat konsumen dan produsen tetap berhubungan walaupun berada di tempat yang berbeda. Media sosial, terutama situs jejaring sosial memberikan ruang maya bagi seseorang untuk berkomunikasi melalui internet dan akan menjadi agen penting sosialisasi konsumen. Seperti yang dilakukan oleh PT.Toyota-Astra Motor yang menggunakan website untuk menunjang penjualannya. Berikut data pengunjung website resmi PT. ToyotaAstra Motor yaitu www.toyota.astra.co.id bulan Januari sampai Maret 2020 :

Tabel 1 Data Pengunjung Website www.toyota.astra.co.id

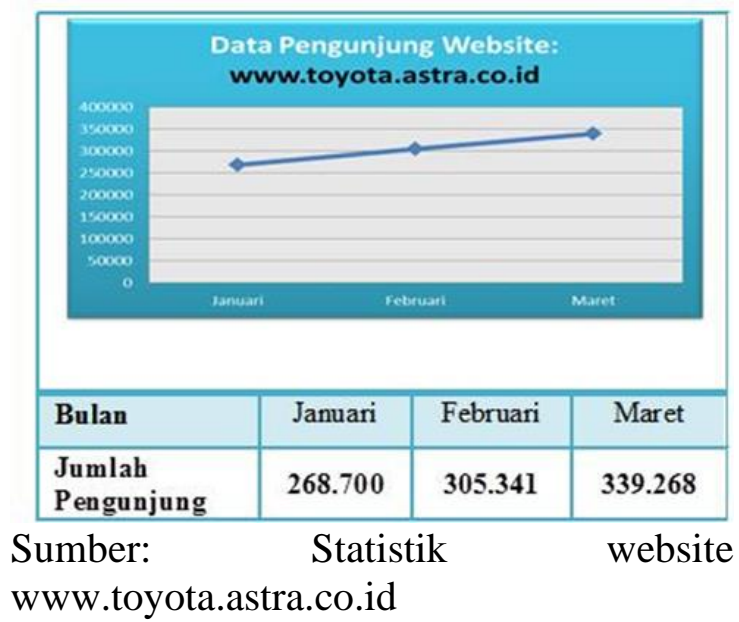


Dari data di atas dapat terlihat bahwa jumlah pengunjung website www.toyota.astra.co.id tergolong banyak dengan jumlah rata-rata untuk triwulan pertama tahun 2020 sebanyak 304.436 pengunjung. Dan terjadi kenaikan pengunjung dari bulan Januari sampai Februari sebesar 12 persen, sedangkan kenaikan pengunjung bulan Februari sampai Maret sebesar 10 persen. Hal ini menggambarkan banyaknya potensi penjualan melalui e-commerce. Penggunaan e-commerce yang memakan biaya cukup banyak seharusnya juga dibarengi dengan kenaikan penjualan, disini perlu adanya pengukuran efektifitas penggunaan $e$-commerce.

Disamping penggunaan $e$ commerce dalam mendongkrak pertumbuhan penjualan, perusahaan juga sering menggunakan promotion sale sebagai salah satu solusi memenangkan persaingan. Dengan menggunakan harga promo yang tepat perusahaan akan lebih mudah untuk mendapatkan konsumen. Harga promo dapat ditetapkan oleh perusahaan sesuai dengan kebutuhan dan anggaran yang telah ditetapkan oleh perusahaan. Yang seharusnya terjadi dalam sebuah perusahaan adalah ketika perusahaan menurunkan harga penjualan, maka volume penjualan pun harusnya semakin tinggi pula.

Berikut harga promo yang diadakan oleh PT. Toyota-Astra Motor:

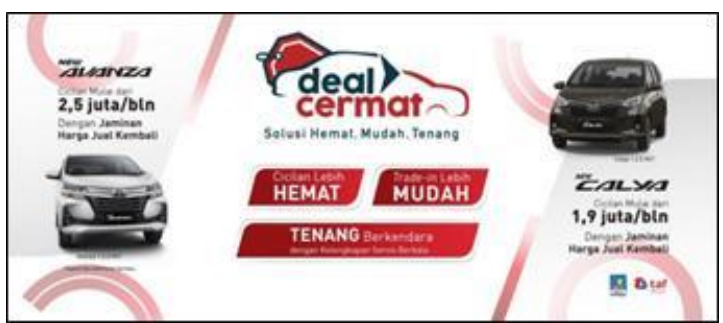

\section{Gambar Promo Deal Cermat bulan Februari}

Hampir tiap 2 bulan sekali PT.Toyota-Astra Motor mengadakan promo penjualan. Hal ini tidak terlepas dari banyaknya pesaing di dunia otomotif, baik yang sudah lama bergerak di bidang otomotif nasional maupun perusahaan pendatang yang berusaha mengambil alih pelanggan. PT. Toyota-Astra Motor masih mengandalkan harga promo sebagai salah satu strategi pemenangan persaingan pasar. Adapun tujuan dilakukannya penelitian ini yaitu pertama, Untuk menganalisis pengaruh E-commerce terhadap penjualan PT.Toyota-Astra Motor. Kedua, Untuk menganalisis pengaruh Promotion sale terhadap penjualan PT.Toyota-Astra Motor. Ketiga, Untuk menganalisis besarnya pengaruh E-commerce dan Promotion sale terhadap penjualan PT.Toyota-Astra Motor.

\section{KAJIAN PUSTAKA DAN PENGEMBANGAN HIPOTESIS \\ E-commerce}

Dikutip dari Vermaat (2017) dalam buku Menjelajah dunia komputer fundamental, E-commerce merupakan transaksi bisnis yang terjadi dalam jaringan elektronik seperti internet. Siapapun yang mempunyai jaringan internet dapat berpartisipasi dalam $e$ commerce. E-commerce juga melibatkan aktifitas yang berhubungan dengan proses transaksi elektronik seperti transfer dana elektronik, pertukaran data elektronik, sistim pengolahan data inventori yang dilakukan dengan sistem komputer ataupun jaringan komputer dan lain sebagainya. Dalam teknologi informasi $e$ commerce dapat dikategorikan sebagai bagian dari e-business dimana e-business memiliki cakupan lebih luas baik dari segi aktifitas.

\section{Promotion Sale}

Promosi penjualan (sales promotion) yaitu insentif jangka pendek untuk mendorong keinginan mencoba atau pembelian produk dan jasa. Promosi penjualan terdiri dari semua kegiatan pemasaran yang mencoba merangsang terjadinya aksi pembelian suatu produk yang cepat atau terjadinya pembelian dalam waktu yang singkat. Promosi penjualan yang berorientasai konsumen 
menggunakan kupon, premium, contoh gratis, kontes/undian, potongan harga setelah pembelian, dan lain-lain (Shimp 2016:131).

\section{Penjualan}

Menurut Rudianto (2019:104), Penjualan merupakan sebuah aktivitas yang mengakibatkan arus barang keluar perusahaan sehingga perusahaan memperoleh penerimaan uang dari pelanggan.

\section{METODE PENELITIAN Populasi dan Sampel}

Dalam penelitian ini penulis menggunakan metode penelitian deskriptif kuantitatif dengan pendekatan asosiatif. Penelitian kuantitatif adalah metode penelitian yang berdasarkan pada filsafat positivisme, digunakan untuk meneliti pada populasi atau sampel tertentu, pengumpulan data menggunakan instrument penelitian, analisis data bersifat kuantitatif atau statistik.

Pada metode asosiatif penulis mengharapkan dapat mengetahui bagaimana hubungan atau pengaruh variabel e-commerce (X1) dan promotion sale (X2) terhadap penjualan (Y) yang merupakan variabel-variabel yang akan penulis teliti.

Uji Validitas digunakan untuk mengukur sah atau valid tidaknya suatu kuesioner. Suatu kuesioner dikatakan valid jika pertanyaan dalam kuesioner mampu untuk mengungkapkan sesuatu yang akan diukur oleh kuesioner tersebut menurut Ghozali (2001) dalam Sujarweni (2015). Uji Reliabilitas dilakukan terhadap item pertanyaan yang dinyatakan valid. Uji ini digunakan untuk mengukur suatu kuesioner yang merupakan indikator dari variabel. Suatu kuesioner dikatakan reliabel atau handal jika jawaban seseorang terhadap pernyataan adalah konsisten atau stabil dari waktu ke waktu.

Uji Asumsi Klasik digunakan untuk menguji, apakah model regresi yang digunakan dalam penelitian ini layak untuk diuji atau tidak. Persamaan tersebut harus dapat diterima secara ekonometrik maka harus memenuhi asumsi klasik, antara lain : Uji normalitas dilakukan untuk mengetahui apakah data memiliki distribusi normal atau mendekati normal dengan melihat Kurva Normal P-P Plot. Data dapat disimpulkan bahwa terdisribusi normal apabila dalam grafik normal p-plot terlihat titik menyebar di sekitar garis diagonal dan penyebarannya tidak terlalu jauh atau melebar. Berdasarkan gambar diatas maka dapat disimpulkan bahwa dalam grafik normal p-plot terlihat titik menyebar di sekitar garis diagonal dan penyebarannya tidak terlalu jauh atau melebar, sehingga data dapat digunakan dalam pengujian dengan model regresi linear berganda untuk penelitian ini. Untuk itu diperlukan pengujian lebih akurat yaitu dengan metode non parametric one sample kolmogorov-smirnov (one sample K-S). Jika nilai K-S signifikan maka residual tidak normal, tetapi jika K-S tidak signifikan maka residual terdistribusi secara normal (Ghozali, 2015). Jika signifikan lebih dari 0,05 maka residual terdistribusi secara normal. Berdasarkan hasil pengujian diketahui bahwa hasil uji kolmogrov smirnov dengan nilai signifikan 0,274 (Asymp. Sig. (2-tailed)), artinya dapat disimpulkan bahwa residual terdistribusi secara normal, karena $\mathrm{p}$ value $>0,05$. Uji multikolineritas digunakan untuk mengetahui ada tidaknya multikolinieritas dengan menyelidiki besarnya interkorelasi antara variabel bebasnya. Ada tidaknya multikolinieritas dapat dilihat dari besarnya Tolerance Value dan Variance Inflation Factor (VIF). Jika nilai Tolerance Value $\geq 0,10$ atau sama dengan nilai VIF $\leq 10$. Setelah dilakukan pengujian dapat diketahui bahwa variabel E-commerce, Promotion Sale dan Penjualan memiliki nilai Tolerance $>0,1$ dan nilai VIF $<10$, maka dapat disimpulkan tidak terjadi Multikolinieritas. Berdasarkan hasil uji heterokedastisitas menunjukkan bahwa grafik Scatter Plot antara variabel 
dependen dan variabel residualnya. Grafik ini menunjukkan pola penyebaran titik titik. Jika titik - titik menyebar di atas dan di bawah 0 pada sumbu Y, berarti tidak terjadi heteroskedastisitas pada data yang digunakan. Berdasarkan gambar di atas terlihat bahwa titik - titik dalam gambar menyebar secara acak ke atas dan ke bawah angka 0 (nol) pada sumbu Y (tidak membentuk pola yang sistematis). Hal ini berarti tidak terjadi heterokedastisitas dalam model regresi ini.

\section{Metode Analisis Data}

Analisis Koefisien Korelasi Menurut Siregar (2017:251) koefisien korelasi adalah bilangan yang menyatakan kekuatan antara dua variabel atau lebih atau juga dapat menentukan arah dari kedua variabel. Analisa Regresi Linear Berganda Penelitian ini bertujuan melihat pengaruh antara variabel independen dan variabel dependen dengan skala pengukuran atau rasio dalam suatu persamaan linier, dalam penelitian ini digunakan analisis regresi berganda yang diolah dengan perangkat lunak SPSS 19 Ghozali (2005) dalam Sujarweni (2015:227).

$$
\ddot{\mathrm{Y}}=\mathrm{a}+\mathrm{b} 1 \mathrm{X} 1+\mathrm{b} 2 \mathrm{X} 2+\mathrm{e}
$$

Dimana :

$\begin{array}{ll}\mathrm{a} & =\text { Konstanta } \\ \mathrm{Y} & =\text { Penjualan } \\ \mathrm{b} 1 \ldots \mathrm{b} 4 & =\text { Koefisien regresi } \\ \mathrm{X} 1 & =\text { E-commerce } \\ \mathrm{X} 2 & =\text { Promotion Sale } \\ \mathrm{e} & =\text { Residual. }\end{array}$

\section{HASIL DAN PEMBAHASAN Uji Validitas}

Uji Validitas dilakukan untuk menguji apakah pernyataan dalam kuesioner dapat dijadikan suatu ukuran yang menunjukan tingkat kevalidan atau kesahihan suatu instrumen. Valid berarti instrumen tersebut dapat digunakan untuk mengukur apa yang seharusnya diukur. Kriteria yang digunakan adalah apabila hasil $\mathrm{r}_{\text {hitung }}>\mathrm{r}_{\text {tabel }}$ maka valid. Hasil dari uji validitas data dapat dilihat dalam tabel berikut:

Tabel 2 Hasil Uji Validitas

\begin{tabular}{|c|c|c|c|c|c|}
\hline \multirow{2}{*}{ Variabel } & \multicolumn{3}{|c|}{$\mathrm{r}_{\mathrm{K} \text { Han }}$} & \multirow{2}{*}{$\begin{array}{l}\mathrm{r}_{\text {Tutel }} \\
1 \% \%\end{array}$} & \multirow{2}{*}{ Keter angan } \\
\hline & $\mathrm{Xl}$ & $\mathrm{x} 2$ & $\mathbf{Y}$ & & \\
\hline 1 & 0.784 & 0.735 & 0.677 & 0.317 & Valid \\
\hline 2 & 0.766 & 0.772 & 0.641 & 0317 & Valid \\
\hline 3 & 0.743 & 0.755 & 0.460 & 0317 & Valid \\
\hline 4 & 0.807 & 0.782 & 0.731 & 0317 & Valid \\
\hline 5 & 0.753 & 0.773 & 0.741 & 0317 & Valid \\
\hline 6 & 0.712 & 0.854 & 0.846 & 0317 & Valid \\
\hline 7 & 0.734 & 0.801 & 0.892 & 0.317 & Valid \\
\hline 8 & 0.759 & 0.791 & 0.843 & 0.317 & Valid \\
\hline 9 & 0.782 & 0.821 & 0.835 & 0.317 & Valid \\
\hline 10 & 0.867 & 0.781 & 0.851 & 0317 & Valid \\
\hline
\end{tabular}

Sumber: Data primer yang diolah dengan SPSS 19.0, 2020

Dari tabel di atas, diperoleh data yang menyatakan bahwa seluruh pernyataan valid, karena nilai korelasi ( $r_{\text {hitung }}$ ) di atas nilai $r_{\text {tabel }}$ sebesar 0.317 yang diperoleh dari $\mathrm{r}$ product moment dengan level of significant $1 \%$ dan $\mathrm{df}=\mathrm{n}$ dengan $\mathrm{n}$ sebanyak 65 responden.

\section{Hasil Uji Reabilitas}

Uji Reliabilitas digunakan untuk menguji apakah suatu instrumen dalam penelitian dapat dipercaya untuk digunakan sebagai alat pengumpul data serta untuk mengetahui sejauh mana hasil pengukuran tetap konsisten.

Tabel 3 Hasil Uji Reliabilitas

\begin{tabular}{|l|c|l|l|}
\hline \multicolumn{1}{|c|}{ Variabel } & $\begin{array}{c}\text { Chronbach's } \\
\text { Alpha }\end{array}$ & Batasan & Keterangan \\
\hline $\begin{array}{l}\text { E-commerce } \\
\text { (X1) }\end{array}$ & 0.924 & 0.600 & Reliabel \\
\hline $\begin{array}{l}\text { Promotion } \\
\text { sale (X2) }\end{array}$ & 0.932 & 0.600 & Reliabel \\
\hline Penjualan (Y) & 0.915 & 0.600 & Reliabel \\
\hline
\end{tabular}

Sumber: Data primer yang diolah dengan SPSS 19.0, 2020

Tabel di atas memperlihatkan Cronbach's Alpha masing-masing bernilai 
0,924, 0,932 dan 0,915. Hal ini menunjukan bahwa nilai Cronbach's Alpha lebih besar dari 0,600, berarti semua pernyataan yang berhubungan dengan $e$ commerce dan promotion sale terhadap penjualan dinyatakan reliabel.

\section{Tabel 4. Rangkuman Hasil Analisis Regresi Linier Berganda}

\begin{tabular}{|l|c|c|c|}
\hline \multicolumn{1}{|c|}{ Hipotesis } & Nilai (t- statistik) & Sign. & Ket \\
\hline Constant & 2.092 & 0.041 & - \\
\hline E-Commerce (H1) & 1.069 & 0.289 & Ditolak \\
\hline Promotion sale (H2) & 6.511 & 0.000 & Diterima \\
\hline Adjusted R- squared & \multicolumn{3}{|c|}{0.650} \\
\hline Prob F Statistik & \multicolumn{3}{|c|}{60.507} \\
\hline
\end{tabular}

Sumber: Data diolah SPSS, 2020

\section{Pengaruh E-Commerce Sale Terhadap Penjualan}

Hasil analisa $\mathrm{Y}=6,867+0,122 \mathrm{X} 1$ $+0,721 \mathrm{X} 2$ berarti setiap peningkatan 1 nilai pengaruh e-commerce maka nilai penjualan terpengaruh sebesar 0,122 artinya jika e-commerce (X1) mengalami kenaikan 1 satuan maka kontribusi terhadap penjualan (Y) akan meningkat sebesar $12,2 \%$. Koefisien bernilai positif artinya e-commerce (X1) berpengaruh positif terhadap penjualan (Y), semakin meningkat e-commerce maka semakin tinggi penjualan. Hal tersebut dikarenakan adanya peran positif e-commerce berupa:

(1)Media yang interaktif, desain grafis, teks gambar dan suara di website mampu menampilkan informasi produk dengan lengkap dan menarik. (2) Fleksibel yaitu konsumen dapat melakukan transaksi dari berbagai lokasi, baik rumah, kantor, warnet atau tempat lainnya. (3) Konsumen juga tidak perlu berdandan rapi seperti pada perdagangan tradisional umumnya. (4) Perluasan pasar yaitu jangkauan pemasaran menjadi semakin luas, tidak terbatas oleh area geografis dimanapun perusahaan berada. (5) Efektif yaitu konsumen dapat memperoleh informasi tentang produk yang dibutuhkannya dan bertransaksi dengan cara yang cepat dan murah. (6) Aman secara fisik yaitu konsumen tidak perlu mendatangi toko tempat perusahaan menjajakan barangnya dan ini memungkinkan konsumen dapat bertransaksi dengan aman, sebab di daerah tertentu mungkin sangat berbahaya jika berkendara dan membawa uang tunai dalam jumlah yang besar. (7) Efisiensi yaitu konsumen tidak perlu mengeluarkan tenaga lebih untuk mendatangi toko untuk membeli produk. (8) Perluasan jaringan mitra bisnis artinya dengan adanya $e$ commerce mempermudah bagi perusahaan untuk memperbanyak jaringan bisnis yang nantinya akan membantu penjualan produk atau meningkatkan penjualan produk.

\section{Pengaruh Promotion Sale Terhadap Penjualan}

Hasil analisa $\mathrm{Y}=6,867+0,122 \mathrm{X} 1$ $+0,721 \mathrm{X} 2$ berarti setiap peningkatan 1 nilai pengaruh promotion sale maka nilai penjualan terpengaruh sebesar 0,721 artinya jika promotion sale (X2) mengalami kenaikan 1 satuan maka kontribusi terhadap penjualan (Y) akan meningkat sebesar $72,1 \%$. Koefisien bernilai positif artinya promotion sale (X2) berpengaruh positif terhadap penjualan (Y), semakin meningkat promotion sale maka semakin tinggi penjualan. Hal tersebut dikarenakan adanya peran positif promotion sale berupa:

(1)Adanya rasa senang dan rileks yang dirasakan konsumen ketika mendapatkan harga promo yang dapat meningkatkan minat pembelian. (2) Psikologi harga yang menjadikan konsumen lebih termotivasi melakukan pembelian saat mendapatkan diskon. (3) Lebih hemat, dengan adanya harga promo konsumen dapat membeli produk dengan harga yang lebih murah dibandingkan harga normal. (4) Adanya keuntungan lebih dari harga promo berupa potongan cicilan kredit kendaraan. (5) Adanya keuntungan lebih dari harga promo berupa gratis service berkala. (6) Adanya keuntungan lebih dari harga promo berupa gratis aksesoris kendaraan. (7) Mendapatkan cashback atau hadiah uang 
tunai. (8) Adanya keuntungan lebih dari harga promo berupa bonus asuransi kendaraan.

\section{KESIMPULAN}

Berdasarkan hasil penelitian dan pembahasan mengenai pengaruh ecommerce dan promotion sale terhadap penjualan PT.Toyota-Astra Motor, maka penulis dapat menarik kesimpulan sebagai berikut: Pertama, Berdasarkan hasil uji statistik yang telah dilakukan menunjukkan adanya pengaruh positif ecommerce terhadap penjualan, artinya ecommerce tidak berpengaruh signifikan terhadap penjualan, artinya e-commerce tidak berpengaruh signifikan terhadap penjualan PT.Toyota-Astra Motor. Kedua, Berdasarkan hasil uji statistik yang telah dilakukan menunjukkan adanya pengaruh positif promotion sale terhadap penjualan, artinya promotion sale berpengaruh signifikan terhadap penjualan PT.ToyotaAstra Motor. Ketiga, Berdasarkan analisa yang telah penulis lakukan maka diperoleh simpulan bahwa secara simultan variabel independen (e-commerce dan promotion sale) berpengaruh secara signifikan terhadap penjualan PT.Toyota-Astra Motor.

\section{DAFTAR PUSTAKA} Jakarta: Gramedia Widiasarana Indonesia.

Ika dan Abdul. 2015..Prinsip Dasar Ekomoni Islam. Jakarta: Prenada Media Group. h. 44

Kotler, Philip diterjemahkan oleh Basu Swastha. 2017. Manajemen Pemasaran Moderen. Jakarta: FE UI.

Dirvi Surya Abbas, Arry Eksandy. (2020). The Effect Of Effective Tax Rate, Tunneling Incentive, And Exchange Rate On Company Decisions To Transfer Pricing : Food And Consumption SubSector Companies Listed On The
Indonesia Evidence. Palarch's Journal Of Archaeology Of Egypt / Egyptology, 17(7), 14430-14442. Retrieved From Https://Archives.Palarch.N1/Index. $\mathrm{Php/Jae/Article/View/5486}$

Kotler, Philip diterjemahkan oleh A.B Susanto. Manajemen Pemasaran Indonesia (Jakarta: Salemba Empat, 2015), h.9

Lestari, Leni. 2017. Pengaruh ECommerce Terhadap Volume Penjualan Pada Online Shop Aneka Kemeja Pria Bekasi. Jurnal Studi Manajemen dan Bisnis.

Rerung, Rintho Rante. 2018. E-Commerce Menciptakan Daya Saing Melalui Teknologi Informasi. Yogayakarta: CV Budi Utama.

Rudianto. 2019. Pengantar Akuntansi. Jakarta: Erlangga.

Satriawan, Robby. 2018. Pengaruh Promosi Terhadap Volume Penjualan Pada Kangaroo Motor Mandiri. Jurnal Studi Manajemen dan Bisnis.

Swastha, Basu dan T. Hani Handoko.2015. Manajemen Pemasaran: Analisa Perilaku Konsumen, cetakan keempat. Yogyakarta: Penerbit BPFE.

Tjiptono, Fandi. 2015. Strategi Pemasaran edisi kedua. Yogyakarta: Andi.

Vermaat, Shelly Chasman (2017:83). Discrovering Computers:

Menjelajah Dunia Komputer Fundamental Edisi 3. Jakarta: Salemba

Wibowo, Radna Andi. 2019. Manajemen Pemasaran. Semarang: Radna Andi Wibowo. 